University of Nebraska - Lincoln

DigitalCommons@University of Nebraska - Lincoln

1994

\title{
Ultrasonic velocities in cores from the Kola superdeep well and the nature of subhorizontal seismic reflections
}

\author{
Lev Vernik \\ Stanford University \\ Stephen Hickman \\ U.S. Geophysical Survey \\ David Lockner \\ U.S. Geophysical Survey \\ Michael Rusanov \\ Nedra Enterprise
}

Follow this and additional works at: https://digitalcommons.unl.edu/usgsstaffpub

Part of the Earth Sciences Commons

Vernik, Lev; Hickman, Stephen; Lockner, David; and Rusanov, Michael, "Ultrasonic velocities in cores from the Kola superdeep well and the nature of subhorizontal seismic reflections" (1994). USGS Staff -Published Research. 409.

https://digitalcommons.unl.edu/usgsstaffpub/409

This Article is brought to you for free and open access by the US Geological Survey at DigitalCommons@University of Nebraska - Lincoln. It has been accepted for inclusion in USGS Staff -- Published Research by an authorized administrator of DigitalCommons@University of Nebraska - Lincoln. 


\title{
Ultrasonic velocities in cores from the Kola superdeep well and the nature of subhorizontal seismic reflections
}

\author{
Lev Vernik \\ Department of Geophysics, Stanford University, Stanford, Calfiornia \\ Stephen Hickman and David Lockner \\ U.S. Geophysical Survey, Menlo Park, Calfiornia \\ Michael Rusanov \\ Nedra Enterprise, Zapolyarny, Russia
}

\begin{abstract}
P$ wave velocity and orthogonally polarized $S$ wave velocities were measured on 12 cores recovered from the Kola superdeep well at depths of 0 to $12 \mathrm{~km}$. Measurements were made along the core axis at a frequency of $1 \mathrm{MHz}$, at confining pressures ranging from 2 to $100 \mathrm{MPa}$, and under dry and water-saturated conditions. Cores were chosen to sample a variety of lithologies and were used to estimate interval velocities based on a simplified geological column of the well. These interval velocities were then compared with sonic log and vertical seismic profile (VSP) data. High-pressure lab velocities correlated primarily with rock composition and texture. These laboratory velocities are generally in good agreement with both sonic log and VSP data, suggesting that extremely low velocities, as measured in unconfined laboratory samples or at low confining pressure, are the result of drilling and core-recovery-induced damage. The magnitude of this microcrack-induced damage generally increases with depth in a stepwise manner but with a few notable inversions. These inversions are characterized by a relatively small reduction in dry unconfined velocities compared to the in situ velocities. We interpret these inversions to be due to localized in situ stress relief related to faulting, fracturing, and/or hydrothermal alteration. We also observed pronounced $S$ wave splitting in the cores, the analysis of which suggests that the stress relief microcracks tend to be aligned parallel to the foliation in gneisses and amphibolites (dip angle $28^{\circ}-45^{\circ}$ ) rather then being subhorizontal. These observations have important implications for the nature of gently dipping seismic reflections detected in the immediate vicinity of the Kola well.
\end{abstract}

\section{Introduction}

Deep and superdeep continental drilling is critical for improving our understanding of the composition, structure, and physical conditions in the upper crust. Two of the most fundamental problems facing contemporary seismology are understanding the nature of subhorizontal seismic reflectors and layered upper crustal velocity inversions (or wave guides). Both of these features have been observed in the wide-angle seismic reflection and refraction surveys and the vertical seismic profile (VSP) data collected in the vicinity of the Kola well [Litvinenko, 1975; Pavlenkova, 1989]. At Kola,

Copyright 1994 by the American Geophyscial Union.

Paper number 94JB01236.

0148-0227/94/94JB-01236\$05.00 the subhorizontal seismic reflectors are confined largely to depths of 7.5-8.5 km, immediately beneath the 6.8$\mathrm{km}$-deep lithologic boundary separating the Proterozoic metavolcanics and the Archean gneissic basement complex. VSP and acoustic log data reveal a pronounced velocity inversion within the Kola Proterozoic complex at $4.3 \mathrm{~km}$ depth. From this depth to the bottom of the well, in situ $P$ wave velocities are about $500 \mathrm{~m} / \mathrm{s}$ lower than they are throughout much of the shallower section of the well.

While the observations of subhorizontal reflectors and a velocity inversion in the upper crust penetrated by the Kola well are now well established [e.g., Kozlovsky, 1987], the origin and nature of these features are still highly controversial. One interpretation of the Kola low-velocity zone was given by Kremenetsky [1990], who suggested that from 4.3 to $9.5 \mathrm{~km}$ depth there exists a layer with enhanced porosity and microscopic fracturing containing free water. Kremenetsky proposed that 
this layer formed as the result of in situ mineral dehydration and pervasive microscopic hydraulic fracturing during the process of regional metamorphism (see also Kremenetsky and Krivtsov [1991]).

To account for the subhorizontal seismic reflections observed at Kola, Mints et al. [1987] resorted to petrophysical observations [Vernik et al., 1987] in unconfined cores retrieved from depths below $4.5 \mathrm{~km}$. A dramatic increase in porosity and oriented microcracking gave rise to a strong velocity anisotropy in these samples. In particular, a general correlation between these core properties and the severity of stress-induced borehole elongation (breakouts) led Mints et al. to postulate that the reflections clustering at $7.5-8.5 \mathrm{~km}$ are due to subhorizontal dilatant microcracks induced by high contemporary differential stresses. A critical review of this hypothesis is given by Vernik and Nur [1992], who studied ultrasonic velocities and velocity anisotropy of cores retrieved from the Cajon Pass well, located $4 \mathrm{~km}$ from the San Andreas fault in California.

In this paper we address these issues directly by measuring ultrasonic velocities and shear wave splitting on cores from the Kola well over a wide range of confining pressures and then comparing the results with sonic $\log$ and VSP data. We argue that it is unnecessary to appeal to the presence of elevated fluid pressures and pervasive microscopic hydraulic fracturing in the rock at depth surrounding the Kola well. Rather, the general increase in core porosity and the decrease in ultrasonic $P$ and $S$ wave velocities with depth at low confining pressur : are likely the result of sample retrieval effects such as stress relief cracking, thermal cracking, and core disking. Similar conclusions were reached regarding measurements of permeability and electrical resistivity on cores taken from the Kola well [Lockner et al., 1991; Morrow et al., 1994]. Finally, by comparing our laboratory meausurements with sonic log and VSP data, we show that the velocity inversion observed below a depth of $4.3 \mathrm{~km}$ at Kola is most likely the result of variations in bulk chemical composition and foliation-induced seismic anisotropy.

\section{Sample Description and Method}

The geological section of the Kola well can be briefly described as follows [Kozlovsky, 1987]: (1) The borehole penetrated Proterozoic complex rocks from 0 to $6.8 \mathrm{~km}$, with basic composition metavolcanics from 0 $1.0 \mathrm{~km}$, a metasedimentary sequence in the depth range of about 1.0 to $2.8 \mathrm{~km}$, basic metavolcanics from 2.8 to $4.5 \mathrm{~km}$, and intermediate metavolcanics dominating from 4.5 to $6.8 \mathrm{~km}$; and (2) between 6.8 and $12 \mathrm{~km}$ the well intersects an Archean gneiss-migmatite complex with ubiquitous amphibolite bodies up to $30 \mathrm{~m}$ in thickness. Regional metamorphism of Proterozoic age has affected both complexes, effectively obliterating textural differences between the metavolcanics and underlying gneisses. A transition from greenschist to epidote-amphibolite metamorphic facies occurs at 4.3$4.5 \mathrm{~km}$, below which the rock is uniformly foliated due to the preferred orientation of minerals such as mica and amphibole. A brief petrographic description and some physical properties of the samples are given in Table 1. It is clear that the bulk density primarily reflects the mineralogical composition of these rocks. Note also that the porosity as measured in unconfined cores generally increases with depth, being higher in gneisses than in amphibolites at comparable depths.

Velocity measurements were conducted on $12 \mathrm{cy}-$ lindrical samples $(2.5 \mathrm{~cm}$ in diameter, $1.5 \pm 0.3 \mathrm{~cm}$ long) obtained from the Kola well to represent the major lithologies intersected by the well and two samples from nearby surface outcrops. Cores were oriented with

Table 1. Composition, Texture, Bulk Density, and Porosity of Samples Studied

\begin{tabular}{rlllccc}
\hline Depth, & Lithology & Major Minerals $^{*}$ & \multicolumn{1}{c}{ Texture $^{+}$} & $\begin{array}{c}\text { Dip } \\
\text { Angle }\end{array}$ & $\begin{array}{c}\text { Density, } \\
\mathrm{g} / \mathrm{cm}^{3}\end{array}$ & $\begin{array}{c}\text { Porosity, } \\
\%\end{array}$ \\
\hline 0 & gneiss & $\mathrm{Pl}_{10-30}, \mathrm{Q}, \mathrm{Bi}$ & Foliated, m.-gr. & $45^{\circ}$ & 2.67 & 0.37 \\
0 & diabase & $\mathrm{Pl}_{5-10}, \mathrm{cPx}, \mathrm{Chl}$ & Massive, f.m.-gr. & & 2.89 & 0.19 \\
936 & diabase & $\mathrm{Pl}_{5-10}, \mathrm{cPx}$ & Massive, f.-gr. & & 2.98 & 0.11 \\
2948 & metadiabase & $\mathrm{Pl}_{5-10}, \mathrm{Act}, \mathrm{Chl}$ & Massive, f.-gr. & & 2.95 & 0.10 \\
6320 & amphibolite & $\mathrm{Pl}_{10-30}, \mathrm{Hb}, \mathrm{Q}$ & Foliated, f.m.-gr. & $32^{\circ}$ & 2.91 & 0.57 \\
7042 & gneiss & $\mathrm{Pl}_{10-30}, \mathrm{Q}, \mathrm{Bi}, \mathrm{Mu}$ & Foliated f.-gr. & $40^{\circ}$ & 2.67 & 0.87 \\
7651 & amphibolite & $\mathrm{Pl}_{10-30}, \mathrm{Hb}, \mathrm{Q}, \mathrm{Bi}$ & Foliated, f.-gr. & $45^{\circ}$ & 2.94 & 0.78 \\
7670 & gneiss & $\mathrm{Pl}_{10-30}, \mathrm{Q}, \mathrm{Bi}, \mathrm{Mu}$ & Foliated, f.-gr. & $37^{\circ}$ & 2.73 & 1.13 \\
8632 & gneiss & $\mathrm{Pl}_{10-30}, \mathrm{Q}, \mathrm{Bi}$ & Foliated, f.m.-gr. & $40^{\circ}$ & 2.66 & 1.02 \\
8723 & amphibolite & $\mathrm{Pl}_{30-50}, \mathrm{Hb}, \mathrm{Q}$ & Foliated, m.-gr. & $43^{\circ}$ & 3.07 & 0.69 \\
11386 & amphibolite & $\mathrm{Pl}_{30-50}, \mathrm{Hb}, \mathrm{CPx}, \mathrm{Q}$ & Foliated, m.-gr. & $42^{\circ}$ & 2.95 & 0.7 \\
11658 & gneiss & $\mathrm{Pl}_{10-30}, \mathrm{Q}, \mathrm{Bi}, \mathrm{Mu}$ & Foliated, f.-gr. & $28^{\circ}$ & 2.71 & 1.23 \\
\hline
\end{tabular}

"The subscript indicates the amount of anortite component in plagioclase.

${ }^{+}$M.-gr., medium-grained rocks with grain sizes $0.1-1.0 \mathrm{~mm}$; f.-gr., fine-grained rocks with grain sizesess than $0.1 \mathrm{~mm}$.

${ }^{\dagger}$ Porosity is determined by comparing dry and water-saturated densities of unconfined samples and is accurate to within $0.02 \%$. 
the cylinder axis either parallel to the borehole axis (for borehole samples) or vertical (for surface samples). Deviation of the Kola borehole from the vertical averaged about 5 degrees, reaching a maximum of 17 degrees at $10.0-10.5 \mathrm{~km}$. Velocity of compressional $(P)$ and orthogonally polarized shear $\left(S_{\perp}, S_{\|}\right)$waves were measured along the cylinder axis using 1-MHz piezoelectric transducers glued to titanium end caps. Measurements were conducted first on laboratory dry and then fully water-saturated samples at confining pressures $P_{c}$ ranging from 2 to $100 \mathrm{MPa}$. Complete sample saturation was achieved utilizing a combination of capillarity effects and pore evacuation. A core plug was first immersed in water to cover $25 \%$ of its height and a vacuum was applied to the sample for 2 hours. The vacuum was then removed and the process repeated at $50 \%, 75 \%$, and $100 \%$ immersion. After the final evacuation, the sample was left immersed in water at atmospheric pressure until the start of the experiment (about 24 hours).

Pore pressure was maintained at $0.1 \mathrm{MPa}$ throughout these experiments so that the effective pressure $P_{\text {ef }}$ was nearly equal to $P_{c}$. Although the maximum confining pressure used in the present study $(100 \mathrm{MPa})$ is considerably less that the calculated effective overburden pressure at $12 \mathrm{~km}(\sim 210 \mathrm{MPa})$, Vernik and Nur [1992] used the data of Lebedev [1975] to suggest that velocities measured in the laboratory at a confining pressure of $100 \mathrm{MPa}$ and room temperature should closely approach the in situ velocities of rocks at upper crustal depths due to the trade-off between the velocity reduction induced by an increase in temperature with depth and the velocity increase resulting from an increase in confining stress with depth. This suggestion is in accord with our observation (see below) that $P$ and $S$ wave velocities measured in the laboratory at $100 \mathrm{MPa}$ are generally in close agreement with in situ velocities determined from sonic log and VSP data.

For anisotropic materials, $S_{\perp}$ and $S_{\|}$are, in fact, quasi-shear due to a superimposed component of longitudinal particle motion. In our experiments, the shear wave transducers were oriented such that the predominant $S_{\perp}$ and $S_{\|}$particle motions were perpendicular to the cylinder axis, with $S_{\perp}$ polarized in the plane normal to foliation and $S_{\|}$polarized parallel to foliation (Figure 1). Such an arrangement allows the extent of shear wave splitting to be determined for the vertical propagation direction. Both $P$ and $S$ wave velocities were determined by picking the first departure (or break) of the amplitude signal from a background level. The accuracy with which $P$ and $S$ wave velocities could be determined was estimated to be approximately $\pm 1 \%$ and $\pm 1.5 \%$, respectively.

\section{Results}

\section{Ultrasonic Velocities in Cores}

The variation in velocities with confining pressure for the most typical samples from our collection is shown in Figures 2, 3, and 4. In the diabase $(936 \mathrm{~m})$ and
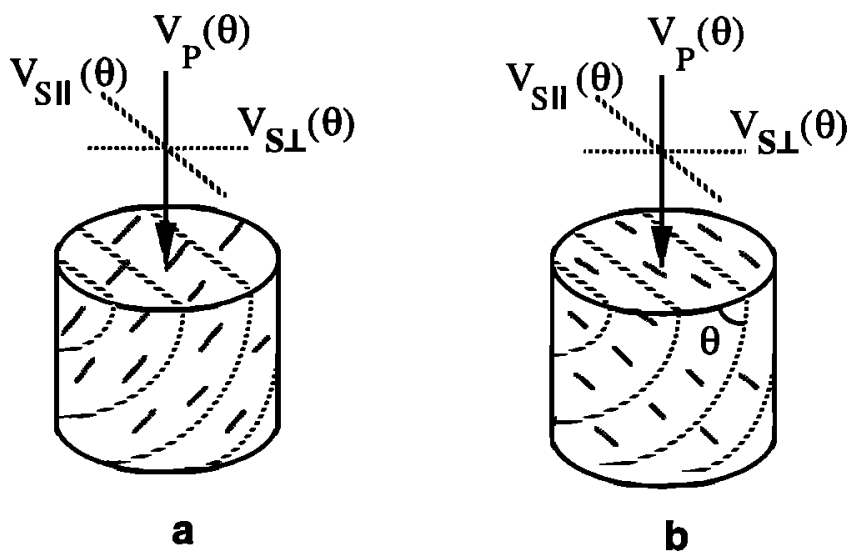

Figure 1. Orientation of cores with respect to propagation and polarization directions of $P, S_{\perp}$, and $S_{\|}$ waves. The foliation dip angles $\theta$ are given in Table 1 and range from $28^{\circ}$ to $45^{\circ}$. (a) Hornblende lineation parallel to the foliation dip direction, as is typical of the lower part of the Proterozoic sequence in the Kola well (e.g., amphibolite from $6320 \mathrm{~m}$ ); (b) hornblende lineation parallel to the foliation strike, as is typical of the Archean portion of the well.

metadiabase (2948 $\mathrm{m}$ ) samples, representing the upper (basic in composition) part of the Proterozoic complex, the $P$ and $S$ wave velocities are uniformly high, showing only a small linear increase with pressure and remaining isotropic at all pressures (Figure 2a). Although these velocities are largely independant of sample saturation, a slight nonlinearity in dry $P$ velocity with confining pressure should be noted for the metadiabase. The foliated and lineated amphibolite $(6320 \mathrm{~m})$, representing the lower part of the Proterozoic complex, shows completely different velocities and variations in velocity with pressure (Figure 2b). The dry $P$ wave velocity in this rock dramatically increases with pressure from 3.6 to $6.4 \mathrm{~km} / \mathrm{s}$, remaining $0.3-0.4 \mathrm{~km} / \mathrm{s}$ lower than $V_{P}$ in rocks from the upper part of the Proterozoic (Figure 2a) at the highest confining pressures used. The magnitude of $V_{P}$ also increases dramatically when this rock is saturated with water (Figure $2 \mathrm{~b}$ ). In addition, the amphibolite demonstrates a clearly anisotropic behavior, with $V_{S \|}<V_{S \perp}$. As discussed below, this anisotropy can be attributed to the $V_{S \perp}$ polarization plane being parallel both to the foliation dip direction and the hornblende lineation direction in this core (Figure 1a). It is interesting to note that $V_{S \perp}$ (and, to a much lesser extent, $\left.V_{S \|}\right)$ at low confining pressures also increases when the rock is saturated, although the effect was much smaller than observed for $P$ velocity.

Figure 3 shows velocities plotted as function of confining pressure for two samples retrieved from the metagabbroic amphibolite bodies abundant in the Archean section of the Kola well (i.e., below $6.8 \mathrm{~km}$ ). In general, these amphibolites display a velocity variation with pressure similar to that of the amphibolite from $6320 \mathrm{~m}$. However, some distinctive features should be emphasized: (1) the dry $P$ and both dry $S$ velocities at low confining pressure (2-5 MPa) decrease with increas- 

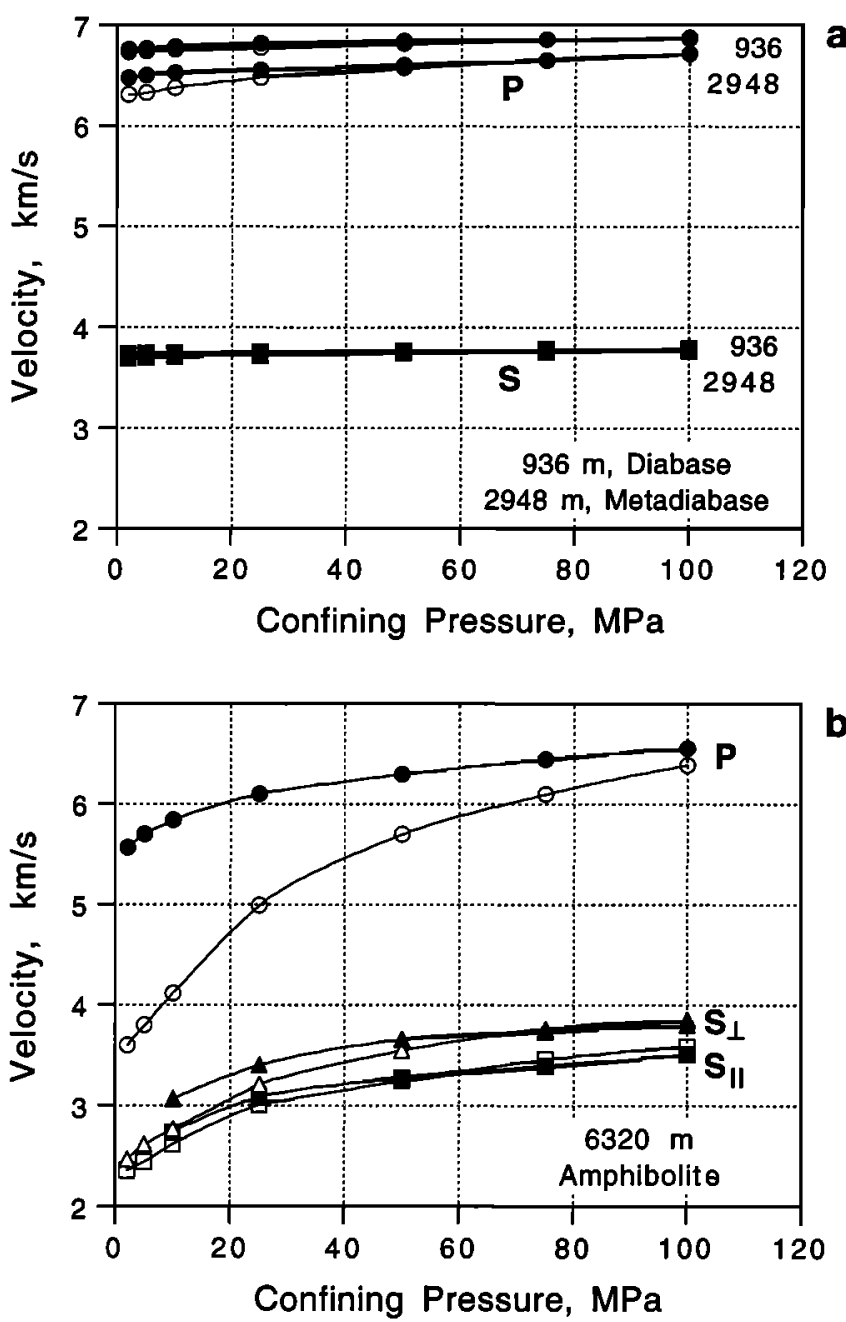

Figure 2. $P$ and $S$ wave velocities measured along the core axis versus confining pressure in dry (open symbols) and saturated (solid symbols) metavolcanics from the (a) upper and (b) lower portions of the Proterozoic Pechenga Complex in the Kola well. In (a) both $S_{\perp}$ and $S_{\|}$were measured but found to be identical to within the resolution of these measurements, thus only one symbol is shown.

ing depth, (2) $V_{S \|}>V_{S \perp}$, which is typical of samples we studied from depths greater than $6.8 \mathrm{~km}$ in the Kola well, where the hornblende lineation is parallel to the foliation strike and hence to the $V_{S \|}$ polarization plane (Figure 1b), (3) the difference between $V_{S \perp}$ and $V_{S \|}$ (i.e., the shear wave anisotropy) increases with depth, and (4) the high-pressure $P$ and $S$ velocities in clinopyroxene amphibolite $(11,386 \mathrm{~m})$ are higher than those recorded for the amphibolites from $6320 \mathrm{~m}$ and $8723 \mathrm{~m}$.

Figure $4 \mathrm{a}$ shows velocities in a typical gneiss from a relatively unweathered surface outcrop of Archean complex as compared (Figure $4 \mathrm{~b}$ ) to a similar lithology from almost $12 \mathrm{~km}$ depth in the Kola well. The former shows high-pressure velocities $\left(V_{P}=6.06 \mathrm{~km} / \mathrm{s}\right.$, $V_{S \perp} \approx V_{S \|}=3.63 \mathrm{~km} / \mathrm{s}$ ) typical of acid gneissic rocks sampled elsewhere [Christensen, 1965] and moderate nonlinear increase in velocity with pressure. The gneiss from a depth of $11,658 \mathrm{~m}$ shows all the features characteristic of other superdeep cores recovered from the Kola hole with two notable exceptions: (1) both $P$ and $S$ velocities are lower than typical for a rock of this composition, even at $100 \mathrm{MPa}$ (compare work by Christensen [1965] and Figure 4a) and (2) about the same increase is observed in both $S$ velocities when the sample is saturated with water at low confining pressures.

The general trend for the pressure sensitivity of the dry $S$ and $P$ wave velocities to increase with increasing depth is emphasized in Figure 5. The increase in pressure sensitivity of the $P$ velocity with depth in the Kola well has been discussed by Vernik et al. [1987] and Vernik and Nur [1992]. These earlier studies used ultrasonic velocity measurements which were made along the core axis at atmospheric pressure and carried out immediately after core recovery. Averaging of those data within geologic units and normalizing by the respective high-pressure values allowed us to generate a depth sec-
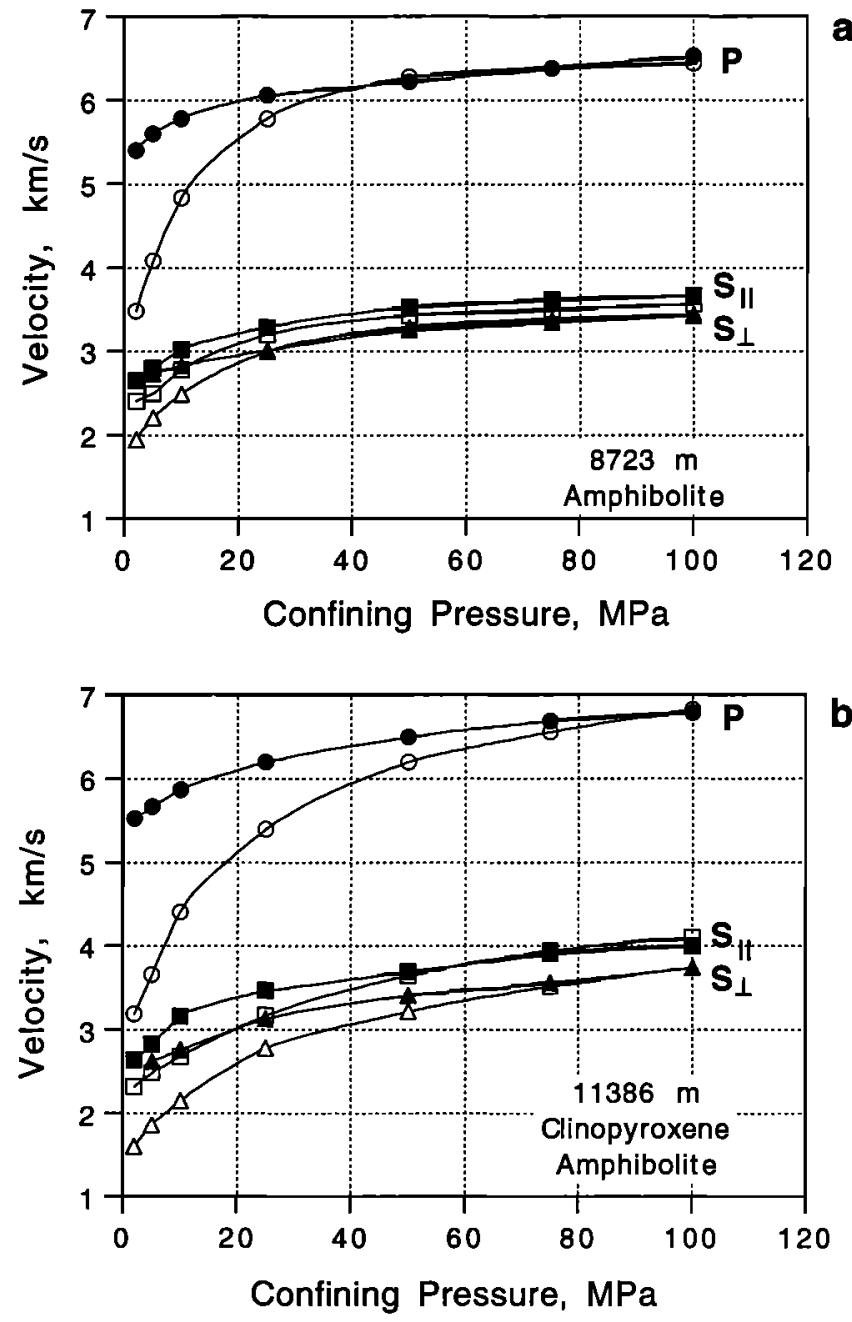

Figure 3. $P$ and $S$ wave velocities measured along the core axis versus confining pressure in dry (open symbols) and saturated (solid symbols) metagabbroic rocks from the Archean section in the Kola well. (a) Amphibolite from a depth of $8723 \mathrm{~m}$ and (b) clinopyroxene amphibolite from a depth of $11,386 \mathrm{~m}$. 

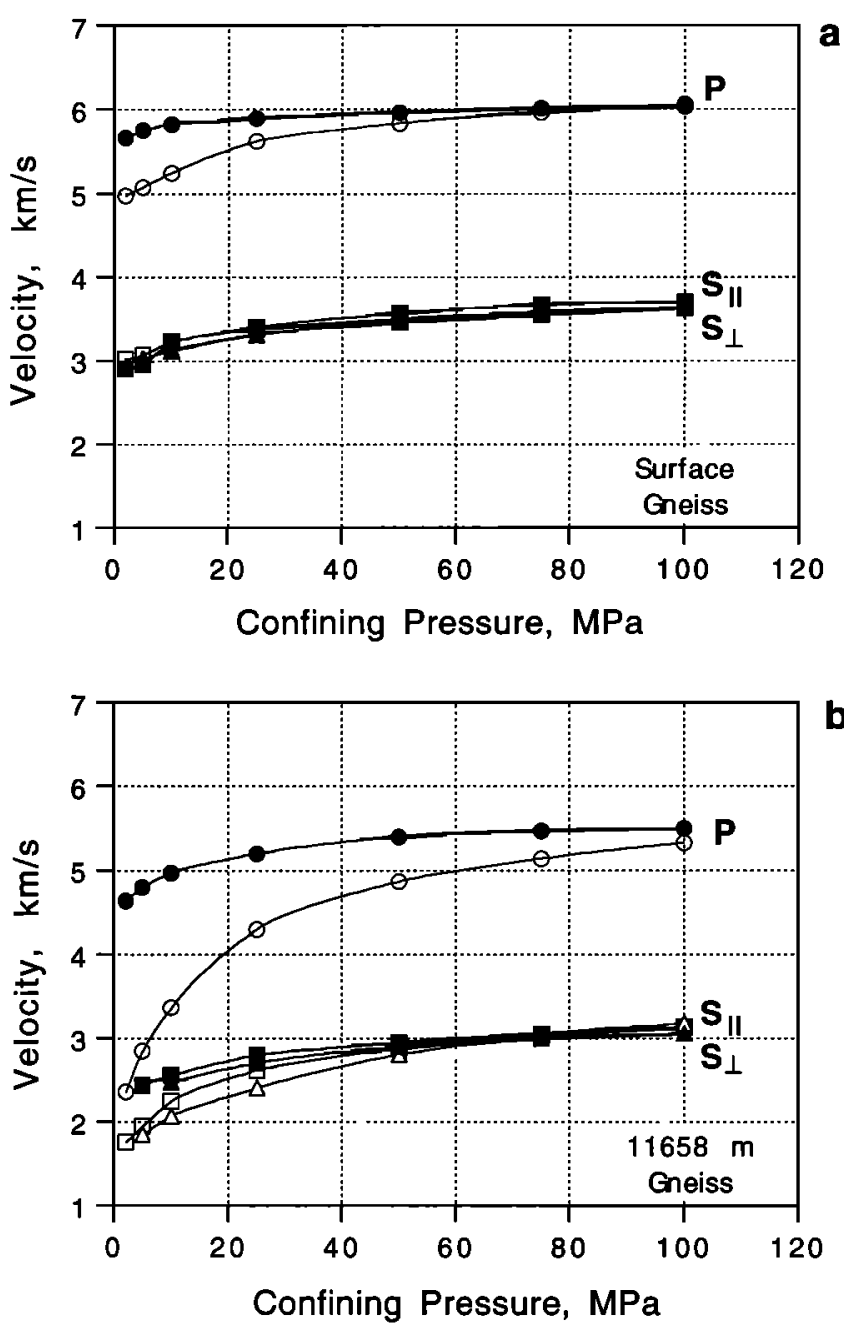

Figure 4. $P$ and $S$ wave velocities measured along the core axis versus confining pressure in dry (open symbols) and saturated (solid symbols) gneisses from the Archean section sampled (a) on the surface and (b) at a depth of $11.7 \mathrm{~km}$ in the Kola well.

tion showing the ratio of $V_{P}$ measured dry at $0.1 \mathrm{MPa}$ to $V_{P}$ measured dry at $100 \mathrm{MPa}$ (reproduced as a solid line in Figure 5). Note that this ratio decreases in a stepwise manner with depth, with some of the sharpest drops occurring at $4.3-4.5 \mathrm{~km}$ and $6.8 \mathrm{~km}$. These drops are roughly coincident with the textural boundary between massive and foliated rocks and the structural and compositional boundary between the Proterozoic and Archean complexes, respectively. Measurements made at low confining pressure (2 $\mathrm{MPa}$ ) in the present study (solid symbols) agree well with those earlier data as well as with the results of Gorbatsevich et al. [1991], even though our data indicate a somewhat lower gradient in the pressure sensitivity of the $P$ wave velocity in the lower half of the well. We interpret the overall decrease in relative velocities (i.e., increase in pressure sensitivity of velocity) with depth observed in both data sets as indicating an increase in the severity of cracking caused by the effects of core retrieval. Measurements of the pressure sensitivity of permeability and electrical resisitivity on cores from the Kola well similarly indi- cate an increase in the density and compliance of stress relief/thermal cracks with depth [Lockner et al., 1991; Morrow et al., 1994].

Several localized intervals in the lower portion of the well between 8 and $11 \mathrm{~km}$ are characterized by spikes on the velocity ratio curve, signifying much smaller damage-related decreases in $V_{P}$ (Figure 5). These intervals normally coincide with a considerable reduction in the severity of stress-induced well bore elongation (breakouts) inferred from the four-arm caliper data in the Kola well [Vernik and Zoback, 1989] and intense faulting and fracturing accompanied by hydrothermal alteration of rocks. Similar intervals exhibiting a reduced intensity of breakout formation associated with fractured or faulted zones have been reported for a number of wells, including the Cajon Pass, California [Vernik and Zoback, 1992], and Gravberg, Sweden [Stephansson et al., 1989], deep holes. In many cases, these anomalous intervals can be explained by reductions in differential stress magnitudes (and stress rotations) induced by slip on faults cutting these wells [Barton and Zoback, 1994]. We think that similar processes might be responsible for the spikes seen in Figure 5, al-

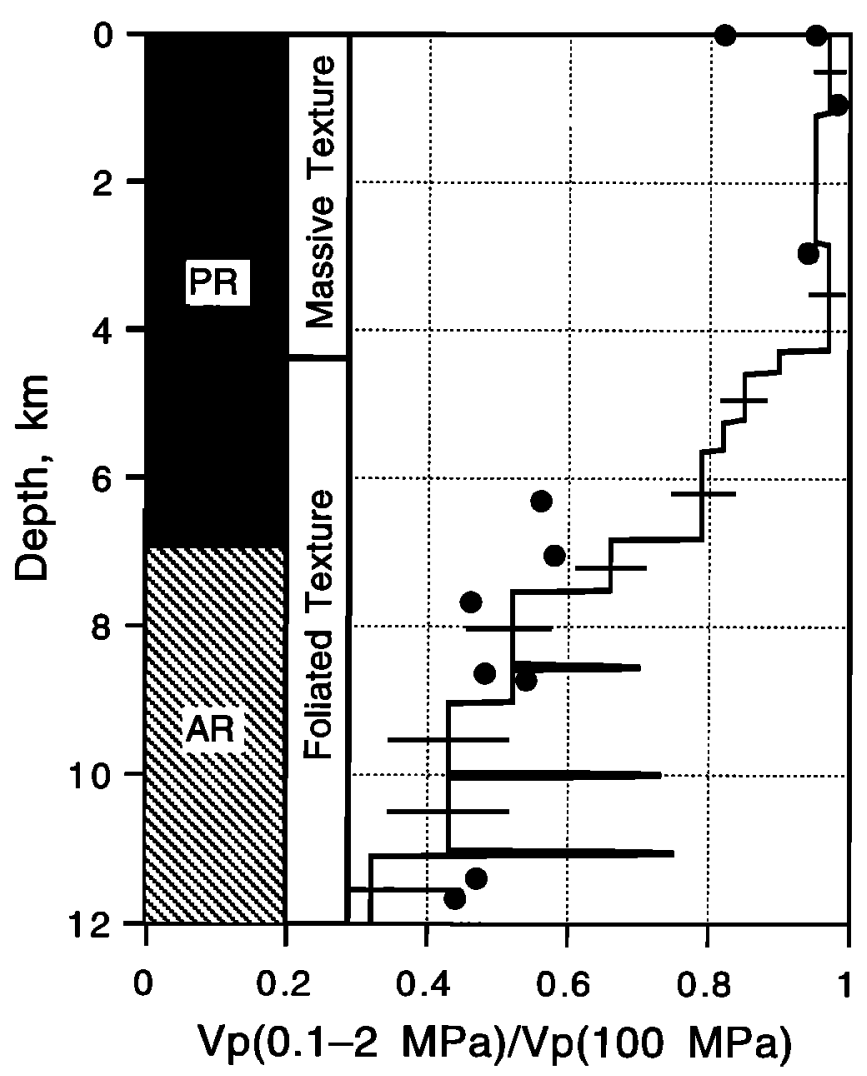

Figure 5. Average dry unconfined $P$ wave velocities (solid line from Vernik et al. [1987]) and dry lowpressure $P$ wave velocities (2 $\mathrm{MPa}$; circles, this study) versus depth in the Kola well. All velocities are normalized to the dry $P$ wave velocities measured in this study at $100 \mathrm{MPa}$. Error bars are derived from multiple measurements by Vernik et al. [1987] using from 18 to 204 samples per depth interval and are shown at \pm 2 standard deviations. 
though it is not clear whether this apparent stress relief is a local phenomenon confined to the fractured well bore wall or represents a stress low in the surrounding rock mass. Unfortunately, none of these intervals is represented in the limited collection discussed in the present paper.

\section{Attitude of Damage-Induced Microcracks in Cores}

Damage-related velocity reduction is also displayed in Figure 6a, where the percent decrease in $S$ velocity $\left(\Delta V_{S}\right)$ in both dry and saturated samples upon unloading from $100 \mathrm{MPa}$ to $5 \mathrm{MPa}$ is plotted versus depth for the lower half of the Kola well. As discussed previously, note that the pressure sensitivity of $V_{S}$ is considerably
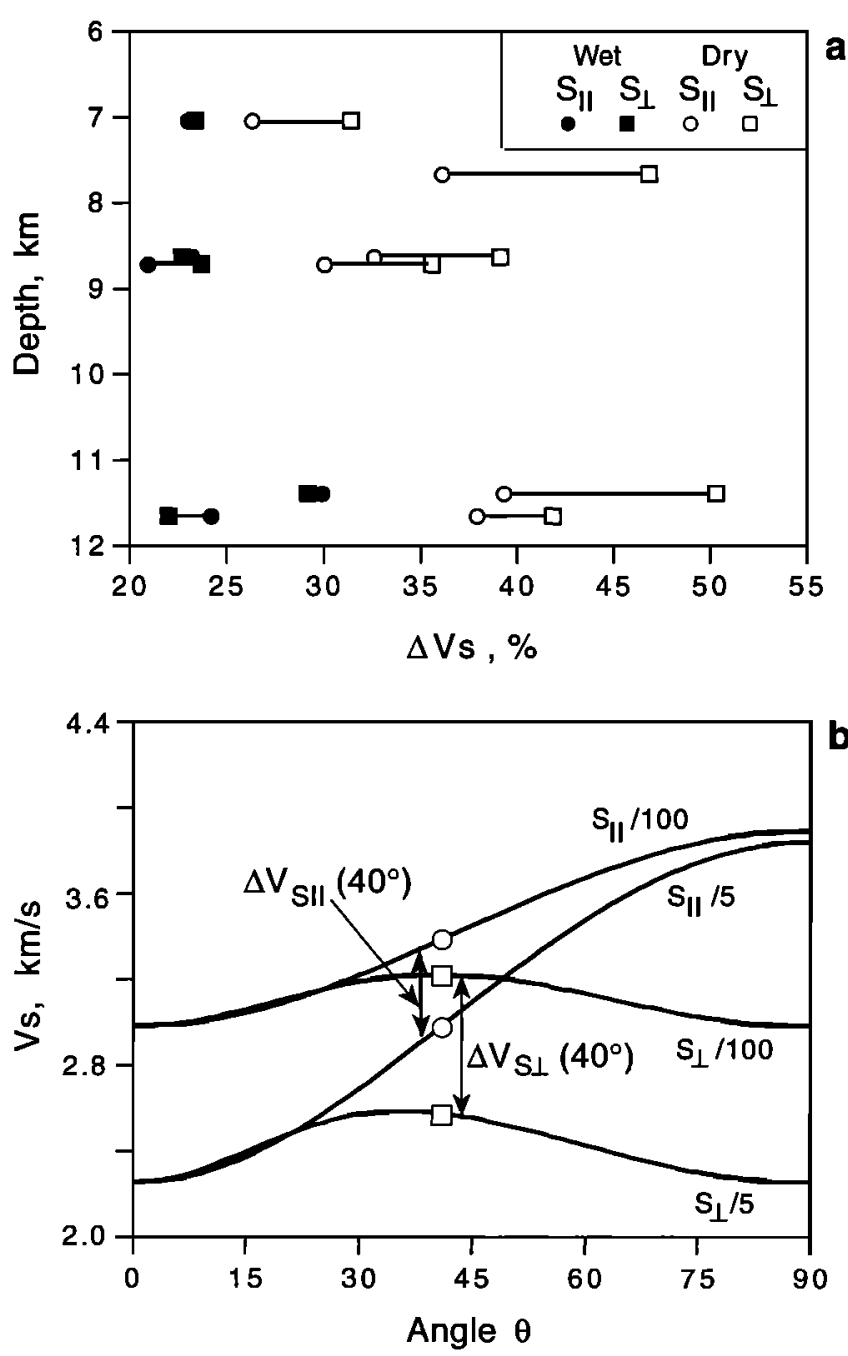

Figure 6. (a) $S$ wave velocity decrease $\left(\Delta V_{S}\right)$ due to drilling and core-recovery-induced damage as confining pressure is decreased from $100 \mathrm{MPa}$ to $5 \mathrm{MPa}$ and (b) a model demonstrating the effect of $S$ wave velocity reduction due to introduction of foliation-parallel microcracks into amphibolite at low (5 MPa) confining pressure. Note that greater $\Delta V_{S}$ values are predicted for $S_{\perp}$ than for $S_{\|}$waves in dry cores for a typical foliation dip angle of $40^{\circ}$. greater for dry than for wet rocks. Of primary interest is the fact that in dry rocks $\Delta V_{S \perp}>\Delta V_{S \|}$, that is, the percent drop in $S_{\perp}$ velocity is always higher than that in $S_{\|}$velocity. Such a relationship is expected for an intrinsically anisotropic rock with microcracks aligned parallel to the symmetry plane (foliation in our case), as is often the case for mica-rich schists and amphibolites at low pressure.

To illustrate this point, we first consider the following model of an intrinsically anisotropic amphibolite without cracks, in which, for simplicity, the rock is assumed to be transversely isotropic (TI) with the bulk density $\rho=3.0 \mathrm{~g} / \mathrm{cm}^{3}$ and the five elastic constants (in GPa) $C_{11}=160, C_{33}=94, C_{66}=45, C_{44}=27$, and $C_{13}=40$. The dispersion equations for shear velocities of TI media are [White, 1965]

$$
\begin{aligned}
V_{S \|}^{2}(\theta) & =\frac{C_{66} \sin ^{2}+C_{44} \cos ^{2} \theta}{\rho} \\
V_{S \perp}^{2}(\theta) & =\frac{A+B-\sqrt{(A-B)^{2}+4 G^{2}}}{2 \rho} \\
A & =C_{11} \sin ^{2} \theta+C_{44} \cos ^{2} \theta \\
B & =C_{44} \sin ^{2} \theta+C_{33} \cos ^{2} \theta \\
G & =\left(C_{13}+C_{44}\right) \sin \theta \cdot \cos \theta
\end{aligned}
$$

We next incorporate the effect of dry microcracks aligned parallel to the rock foliation using Hudson's [1981] formulation

$$
\begin{aligned}
V_{S \perp}^{2}(\theta)= & \beta^{2}\left[1-\frac{16}{3} \eta_{c}\left\{\frac{\lambda+2 \mu}{\lambda+\mu} \sin ^{2} \theta \cdot \cos ^{2} \theta+\right.\right. \\
& \left.\left.\frac{\lambda+2 \mu}{3 \lambda+4 \mu}\left(\cos ^{2} \theta-\sin ^{2} \theta\right)\right\}\right] \\
V_{S \|}^{2}(\theta)= & \beta^{2}\left[1-\frac{16}{3} \eta_{c}\left(\frac{\lambda+2 \mu}{3 \lambda+4 \mu}\right) \cos ^{2} \theta\right]
\end{aligned}
$$

where $\beta$ is the shear velocity of the crack-free matrix, $\lambda$ and $\mu$ are the Lame constants of the rock matrix, and $\eta_{c}=\nu a^{3}$ is the crack density parameter, where $a$ is the crack radius and $\nu$ is the number of cracks per unit volume. In (2), the rock matrix is taken to be isotropic, with the numerical values of $\lambda=C_{13}$ and $\mu=C_{44}$. The crack density parameter can be related to crack porosity $\phi_{c}$ for a given crack aspect ratio $\alpha$, using $\phi_{c}=$ $(4 \pi / 3) \alpha \eta_{c}$. The phase velocities for the intrinsically anisotropic rock with foliation-parallel microcracks can then be computed as

$$
V_{S \perp, S \|}(\theta)=V_{S \perp, S \|}^{i}(\theta)-\left[\beta-V_{S \perp, S \|}^{c}(\theta)\right]
$$

where $V_{S \perp, S \|}^{i}(\theta)$ are the intrinsic velocities given by (1) and $V_{S \perp, S \|}^{c}(\theta)$ are the respective velocities due to cracks given by (2). Because most of the microcracks close at a confining pressure of $100 \mathrm{MPa}$ in the Kola well cores, the shear velocities for $P_{c}=100 \mathrm{MPa}$ can be approximated 
by (1), whereas those of the same rock at $P_{c}=5 \mathrm{MPa}$ and dry conditions are given by (3).

The predicted variations in $S_{\perp}$ and $S_{\|}$velocities with incidence angle obtained in this manner for a rock with a relatively low crack porosity of $0.15 \%$ are shown in Figure $6 \mathrm{~b}$. This analysis indicates that for the $S$ wave incidence angles in the range $28^{\circ}-45^{\circ}$ of interest to us (Table 1), the $S_{\perp}$ velocity drop for the pressure release from $100 \mathrm{MPa}$ to $5 \mathrm{MPa}$ should always exceed that for $S_{\|}$velocity, in agreement with our measurements (Figure 6a). The effect is predicted to be even stronger for the higher crack porosities typical of cores retrieved from the lower half of the Kola well (Table 1). Thus the strong control that the foliation plane exerts on the development of drilling-induced microcracks is reflected in both the magnitude and the presure sensitivity of the velocity anisotropy in cores recovered from great depth in the Kola well. Note that this analysis would lead to the equality $\Delta V_{S \perp}=\Delta V_{S \|}$ if the microcracks were aligned in the horizontal plane, normal to the core axis (Figure 6b).

\section{Comparison of Ultrasonic, Acoustic, and Seismic Velocities}

It is interesting to compare our high-pressure results with sonic log and VSP data [M. Lizinsky, pers. comm., 1980; see also Karus et al., 1987] from the Kola well (Figure 7). It should be noted from the outset that such a comparison should be conducted with caution, especially in the Archean basement because of the great lithological diversity present. In particular, because of the banded structure of the migmatite-gneiss complex and the large number of Proterozoic dikes and sills present in this well below $6.8 \mathrm{~km}$, in situ velocities would be expected to exhibit greater variability than laboratory measurements conducted on a limited number of core samples. Nonetheless, there is a good consistency between the core and VSP/sonic log data, with the exception of the two shallowest and two deepest cores studied. At least for the shallowest core studied, this discrepancy is likely to be caused by the blocky nature of metavolcanics in the upper $0.4 \mathrm{~km}$ of the well, where macroscopic cracks and joints bounding these blocks should affect the in-situ velocities more than measurements on relatively intact core. The large disparity between laboratory and in situ velocities in the lowermost portion of the well is probably an artifact of inadequate sampling of a highly differentiated rock formation (i.e., high-velocity clinopyroxene amphibolite bodies hosted by banded migmatized gneisses). Moreover, the mica gneiss from $11,658 \mathrm{~m}$ was severely damaged during core retrieval, and its velocities may not be representative of the rock in situ, even at $100 \mathrm{MPa}$.

Using estimates of the distribution and thickness of amphibolite bodies in the Archean complex [e.g., $\mathrm{Ko}$ zlovsky, 1987], we used our wet high-pressure (100 MPa) core measurements to calculate $P$ and $S$ wave velocities over discrete depth intervals corresponding to the identified geological units in the lower half of the Kola

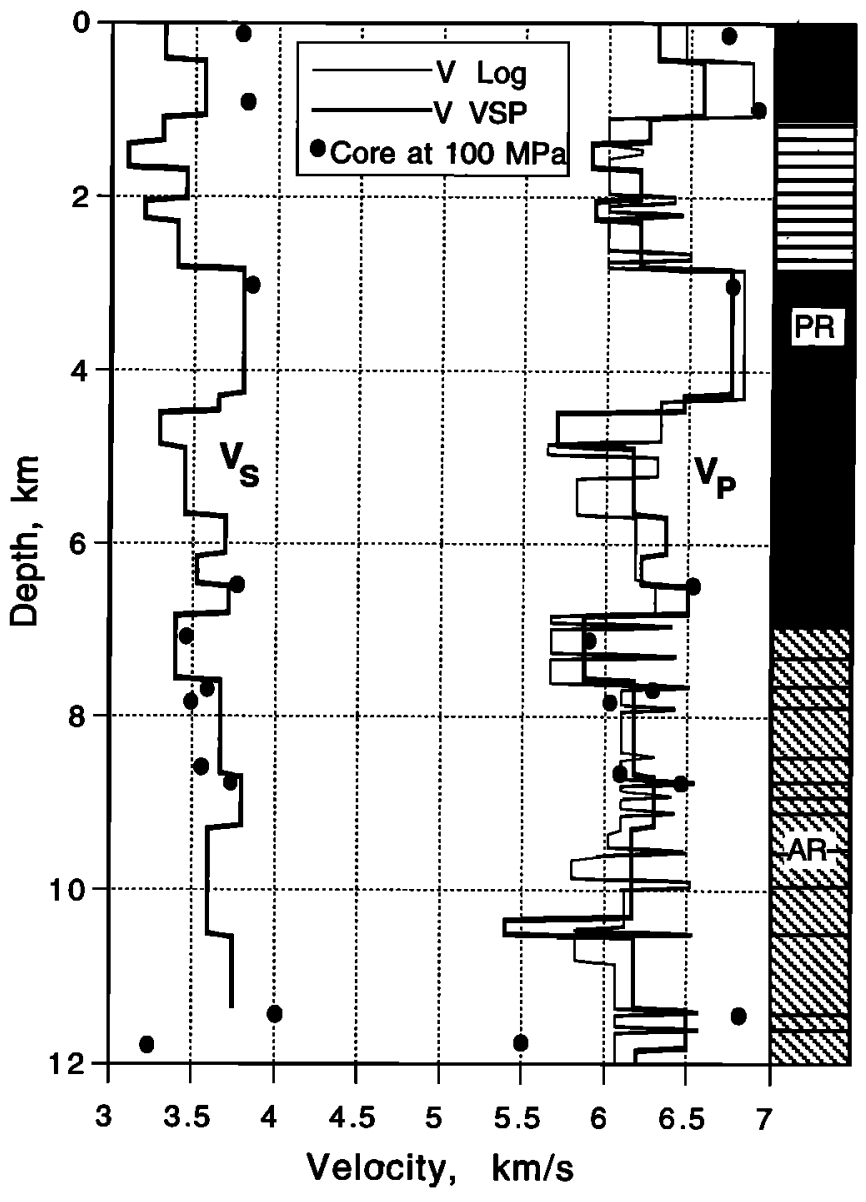

Figure 7. Comparison of our high-pressure (100 MPa) $P$ and $S$ wave velocity measurements made on saturated samples with VSP and sonic log data and a generalized geologic section of the Kola well. The metasedimentary sequence in the interval 1.0-2.8 km (horizontal ruling) is distinguished from the adjacent metavolcanics in the Proterozoic complex by having lower overall $P$ and $S$ wave velocities. Horizontal line segments in the Archean denote the most significant (i.e., thickest) amphibolite bodies.

well (Figure 8). These interval velocities were estimated by first obtaining thickness-weighted velocity-averaged $\left(V_{v}\right)$ and time-averaged $\left(V_{t}\right)$ velocities for each unit using

$$
V_{v}=\sum_{i} V_{i} h_{i} ; \quad V_{t}=\sum_{i} \frac{h_{i}}{V_{i}}
$$

where $h_{i}$ is the apparent thickness of a lithologic layer in the well, and then taking an arithmetic average of these two velocities in a way similar to Hills s1952] average of Voigt and Reuss models. These values are compared with sonic log and VSP data in Figure 8. Good agreement with VSP data, which is also averaged over the same geological units, is clear for $P$ waves. In particular, in both data sets, intervals containing a large density of amphibolite bodies (8.7-9.2 km) display a somewhat higher $V_{P}$, whereas those composed of mica-rich gneisses $(6.9-7.6 \mathrm{~km})$ are characterized by low veloci- 


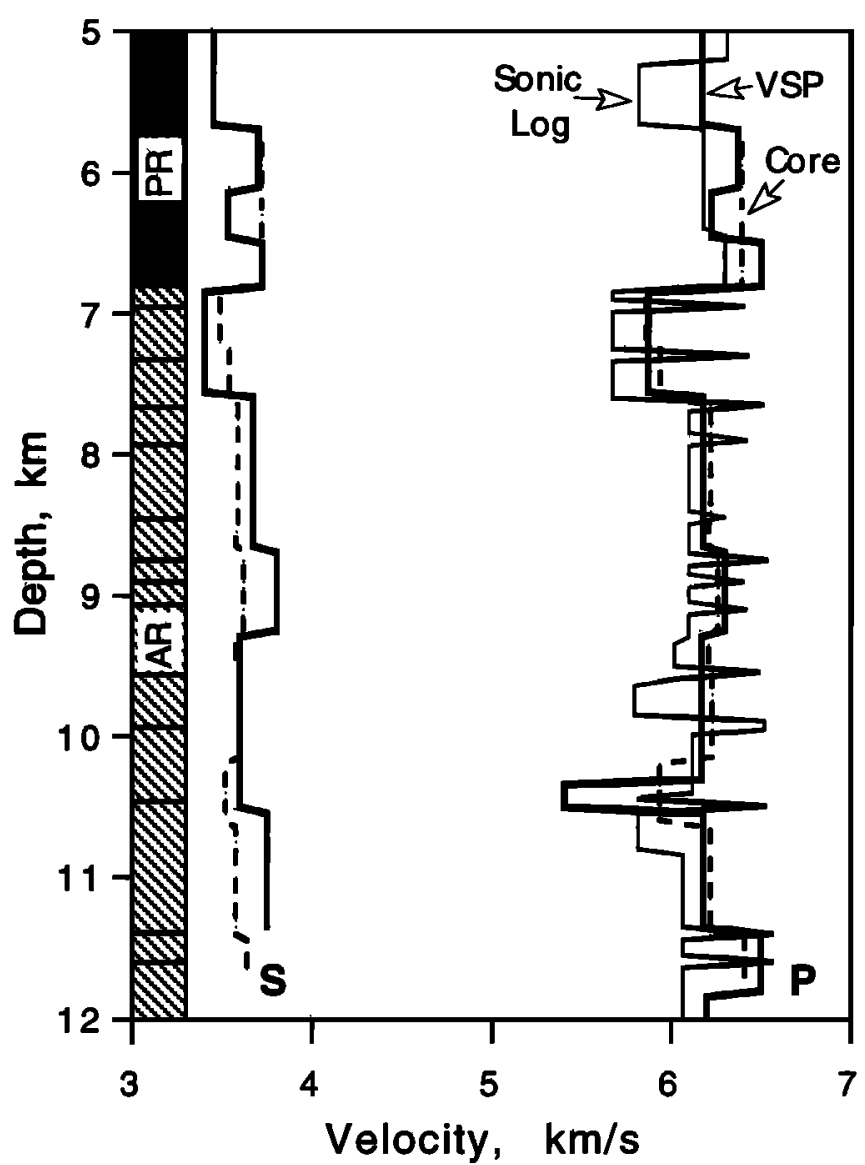

Figure 8. VSP and sonic log data from the lower portion of the Kola well compared to the interval velocities calculated based on amphibolite body abundances (8 to $50 \%$ ) in Archean quartzo-feldspatic gneisses and granites.

ties. Note that the $S$ velocity derived from VSP data shows greater variability with depth than do the core averages.

\section{Discussion}

\section{Velocity Structure of the Crust Sampled by the Kola Well}

The results of ultrasonic velocity measurements conducted along the core axis to $100 \mathrm{MPa}$ confining pressure in conjunction with VSP and acoustic log data indicate a pronounced differentiation of the Kola well section, with the massive basic metavolcanics from 0 to $1.0 \mathrm{~km}$ and 2.8 to $4.3 \mathrm{~km}$ in the Poterozoic complex exhibiting the greatest velocities (Figure 7). The relatively low $P$ and $S$ wave velocities from 1.0 to $2.8 \mathrm{~km}$ depth can be explained simply by the presence of metasedimentary rocks in this interval. The velocity inversion below $4.3 \mathrm{~km}$ depth can be attributed to (1) the volcanics in the lower part of the Proterozoic complex being more intermediate in composition (andesitebasalt) than are the basaltic rocks above $4.5 \mathrm{~km}$ and (2) a transition from greenschist to epidote-amphibolite metamorphic facies occurring at roughly this depth and the associated transformation of massive textures into schistose and foliated textures below $4.3 \mathrm{~km}$. This metamorphic foliation is produced by the preferred orientation of minerals and shows a remarkable consistency in attitude $\left(28^{\circ}-45^{\circ}\right.$ dip angle) from the lower Proterozoic complex well into the Archean complex [Kazansky, 1988]. The compressional velocity reduction of about $0.3 \mathrm{~km} / \mathrm{s}$ at a depth of $4.3 \mathrm{~km}$ (Figure 7) is primarily a result of the textural transformation from massive diabases $\left(V_{P}=6.8 \mathrm{~km} / \mathrm{s}\right)$ to foliated amphibolites $\left(V_{P}=6.5 \mathrm{~km} / \mathrm{s}\right)$ which is superimposed on a relatively constant bulk chemical composition.

Further reductions in velocity due to changes in overall rock composition toward more acid lithologies are observed at $4.5 \mathrm{~km}$ and $6.8 \mathrm{~km}$ (Figure 7), marking the transitions from the upper to the lower series within the Proterozoic volcanic complex and from the Proterozoic volcanics to the Archean gneisses, respectively. The high-pressure vertical laboratory $P$ wave velocity in amphibolites typical of the depth interval $4.5-6.8 \mathrm{~km}$ is about $6.5 \mathrm{~km} / \mathrm{s}$ (Figure $2 \mathrm{~b}$ ). This velocity value agrees with the range $(6.2-6.5 \mathrm{~km} / \mathrm{s})$ obtained in the same interval by acoustic log and VSP surveys and is generally about $0.3-0.6 \mathrm{~km} / \mathrm{s}$ higher than both laboratory and in situ vertical $P$ wave velocity measurements in gneisses below $6.8 \mathrm{~km}$ (Figure 7). It is important to note, however, that the velocity of the fastest shear wave, represented by $S_{\perp}$ mode to a depth of $6.8 \mathrm{~km}$ and the $S_{\|}$mode below this depth (Figures 2, 3, and 4), shows much less variation with depth than that exhibited by the $P$ wave velocity (Figure 7). In particular, the reduction in $S$ wave velocity should have been greater than the reduction in $P$ wave velocity observed below about $4.3 \mathrm{~km}$ if the overall velocity decrease with depth at Kola were related to pervasive microcracks in the crust, as proposed by Kremenetsky [1990].

Application of an equivalent-channel model to measurements of permeability and electrical resistivity on cores from the Kola well indicate that the highly compliant stress relief cracks controlling fluid and current flow at low pressures are largely closed at confining pressures greater than about $100 \mathrm{MPa}$ [Lockner et al., 1991; Morrow et al., 1994]. Thus it is not surprising that laboratory velocity measurements made in the present study at confining pressures of $100 \mathrm{MPa}$ show good agreement with $P$ wave velocities derived from acoustic logs (Figure 7) and that the average velocities calculated over discrete, geologically homogeneous intervals in the well are generally consistent with interval velocities from VSP surveys (Figure 8). Thus it is not necessary to speculate on the existence of the mineral-dehydrationinduced, free-water-filled in situ microcracks to account for the low velocity zone below $4.3 \mathrm{~km}$, as suggested by Kremenetsky [1990]. As discussed above, the observed velocity reduction can simply be explained through the combined effects of variations in lithology and rock fabric. Furthermore, the regional metamorphism to which Kremenetsky attributes these microcracks took place during the Proterozoic (i.e., some 1.5-2 b.y. ago 
[Kazansky, 1988]). Thus it is highly unlikely that free water could have been retained in the gradually cooling rock mass for such a long period of time without these microcracks being fully healed or sealed via mineral dissolution and precipitation processes [e.g., Smith and Evans, 1984; Brantley et al., 1990]. In addition, the pronounced disparity between the $P$ wave velocities inferred from measurements on core samples by Kremenetsky [1990] and both our experiments and the laboratory velocity measurements of Gorbatsevich et al. [1991] suggests that many of the microcracks Kremenetsky attributed to pervasive in situ hydraulic fracturing are actually the result of stress relief and thermal cracking during drilling and core retrieval that were not fully corrected for in his analysis.

In a similar petrophysical study of cores from the KTB well in Germany, Kern et al. [1991] infer that the foliation-controlled microcracks occur in situ to at least $4 \mathrm{~km}$. They found an especially strong discrepancy between the velocities measured at realistic in situ confining pressures in the laboratory and velocities determined from sonic logs over the top $1.0-1.5 \mathrm{~km}$ of the well. They interpret this discrepancy to be related to the abundance of open or partially filled macroscopic natural fractures in the top several hundred meters of the crust, as also observed from the surface to about $0.4 \mathrm{~km}$ in the Kola well. However, we believe that microcracks could also have been introduced into their core samples as a result of core-retrieval-related effects, as described above for the Kola well. In particular, many of the microcracks in our cores were still open at $P_{c}$ close to the effective overburden pressures estimated for the KTB well at 1.0-1.5 km ( 18-26 MPa). Additional work on the KTB cores is warranted to solve the apparent controversy.

\section{On the Origin of Subhorizontal Sesimic Reflections}

Interpretation of the subhorizontal seismic reflections detected by wide-angle reflection and refraction surveys at depths of 6-9 km, and notably clustered around 7.5$8.5 \mathrm{~km}$, is presently a difficult task and requires additional seismic studies (including multioffset VSP and forward modeling of wave propagation as suggested by Pavlenkova [1989]). Mints et al. [1987] proposed that these reflectors were related to tectonically induced dilatancy and even incipient subhorizontal shearing of rocks at depth in response to a dramatic increase in horizontal tectonic stresses immediately below the base of the Proterozoic complex. However, two considerations lead us to reject this hypothesis. First, the observation that velocities in situ are similar to velocities measured at high confining pressures in the laboratory (Figures 7 and 8 ) precludes the existence of pervasive open microcracks at depth. Second, the increase in severity of wellbore elongation below $6.8 \mathrm{~km}$, which is especially notable in the interval from 7.0 to $8.5 \mathrm{~km}$, can be fully explained by a pronounced reduction in rock strength at these depths related to the abundance of mica-rich gneisses [Vernik and Zoback, 1989]. Thus it is not necessary to call on a dramatic increase in the horizontal component of the stress field, as advocated by Mints et al. [1987].

We believe, rather, that the observed increase in microcrack porosity with depth as measured in the core at ambient pressure (Table 1) and the corresponding decrease in the unconfined or low-pressure dry velocity measured on cores relative to in situ values (Figures 5 and 6) can be explained through a number of processes which are widely recognized as exerting a profound influence on crack-sensitive physical properties in cores recovered from deep boreholes (see, for example, Vernik and Nur [1992]). Processes which are expected to introduce cracks into the core during drilling and core recovery include (1) differential elastic rebound of minerals in the core as it is removed from the in situ stress field (stress relief [e.g., Nur and Simmons, 1970; Wang and Simmons, 1978; Kowallis and Wang, 1983; Zang and Berckhemer, 1993]); (2) stress concentrations at the bottom of the hole, ultimately resulting in core rupturing and disking [Obert and Stephanson, 1965; Maury et al., 1988]; and (3) thermal cracking due to core cooling upon recovery [see Bauer and Johnson, 1979; Fredrich and Wong, 1986].

Our measurements and interpretation of the vertical shear wave splitting in the core at low confining pressure suggest that most of the drilling-induced microcracks tend to be aligned parallel to the weak direction in the rock, such as foliation defined by mica flakes in gneiss and hornblende prisms in amphibolite. Thus, even if those cracks were preexisting (as proposed by Mints et al. [1987]) they cannot easily explain the subhorizontal reflectors observed at Kola because of the $30^{\circ}$ or greater dip to the foliation encounted in this well, unless there exist discrete subhorizontal zones of inclined microcracks in the mid to upper crust.

Recent analysis of the seismic reflection and deep seismic sounding (DSS) data in the Kola area by Pavlenkova [1989] suggests that in order to successfully model the high-velocity reflections and the boundary velocity of $V_{b}=6.5-6.6 \mathrm{~km} / \mathrm{s}$ from DSS data at 7.5 $8.5 \mathrm{~km}$ depth one needs to introduce thin, high-velocity layers of limited lateral extent into the geological section. In this respect we should point out that such layers are abundant in the vicinity of the Kola well, in the form of amphibolite bodies equivalent in composition to the basic metavolcanics composing the upper part of the Proterozoic complex. These bodies are normally 5 to $30 \mathrm{~m}$ thick, occur in the depth range from about $6 \mathrm{~km}$ to at least the bottom of the hole, and are most highly concentrated at depths from 7.5 to $9.0 \mathrm{~km}$ (composing $40-50 \%$ of the overall stratigraphic thickness in some intervals). Although the attitudes of these bodies are largely unknown, some of them may occur subhorizontally (e.g., sills) so that the gross, long-wavelength properties of the rock mass at these depths could become highly anisotropic [see Backus, 1962]. This anisotropy would result from the superposition of (1) velocity anisotropy resulting from a high volume percent of imbedded elongated amphibolite bodies, wherein the amphibolites have a measured velocity 
contrast of about $0.4 \mathrm{~km} / \mathrm{s}$ and a density contrast of about $0.3 \mathrm{~g} / \mathrm{cm}^{3}$ compared to the host rocks, and (2) the intrinsic velocity anisotropy typical of mica gneisses and foliated amphibolites. This interpretation is qualitatively consistent with the observation that, in the granitic gneisses at Kola containing $40-50 \%$ amphibolites, the vertical $P$ wave velocities from VSP surveys are about $6.2-6.3 \mathrm{~km} / \mathrm{s}$ whereas the boundary $P$ wave velocity from DSS, which primarily reflects the horizontal velocity of these same units, is about $6.5-6.6 \mathrm{~km} / \mathrm{s}$ [Pavlenkova, 1989].

The existence of free water or saline solutions in the Kola superdeep well is not ruled out by our analysis. Such fluids apparently saturate some of the localized fracture zones intersected by the well to almost $12-\mathrm{km}$ depth [e.g., Kozlovsky, 1987], although the short duration of geochemical anomalies observed during drilling of the Kola well indicates that this fluid phase is distributed in zones of limited extent. Extensive retrograde hydrothermal mineralization is indicated along many of these fracture zones by the presence of lowtemperature mineral phases such as chlorite, albite, and prehnite.

\section{Conclusions}

Measurements made at low confining pressures on cores from 0 to $12 \mathrm{~km}$ depth in the Kola superdeep well indicate that (at ambient laboratory conditions) porosity increases and ultrasonic $P$ and $S$ wave velocities dramatically decrease with increasing depth of sample recovery, at least below about 4-6 $\mathrm{km}$. Strong pressure sensitivity of these velocities, pronounced $S$ wave splitting, and enhancement of velocities upon sample saturation with water are observed at low confining pressures. These results indicate that physical properties in the deeper samples are strongly influenced by pervasive aligned microfractures in the cores. However, at higher confining pressures the $S$ wave splitting is reduced to its intrinsic, fabric-related values, and the sensitivity of velocities to confining pressure and sample saturation largely disappear, indicating that these microcracks are mostly closed at confining pressures of $100 \mathrm{MPa}$. Except for a few localized intervals close to faults and/or hydrothermal alteration zones, these highpressure laboratory velocities correlate well with $P$ and $S$ wave velocities measured in situ using vertical seismic profiling and acoustic logs. This correlation indicates that these microcracks are not present in the rock surrounding the Kola well at depth but, rather, result from processes such as stress relief, thermal cracking, and core disking induced during drilling and core recovery. Thus, we interpret the decrease in in situ $P$ wave velocity observed at a depth of about $4.3 \mathrm{~km}$ in the Kola well as resulting from bulk mineralogical variations and foliation-induced seismic anisotropy and not from pervasive in situ microscopic hydraulic fracturing, as has been sometimes proposed.

Acknowledgments. We wish to thank C. Morrow, D. Schmitt, and C. Williams for many constructive comments and suggestions that greatly improved the manuscript. The work has been supported by the USGS Deep Continental Studies Program contract 92-9960-1530.

\section{References}

Backus, G. E., Long-wave elastic anisotropy produced by horizontal layering, J. Geophys. Res., 67, 4427-4440, 1962.

Barton, C. A., and M. D. Zoback, Stress perturbations associated with active faults penetrated by boreholes: Possible evidence for near-complete stress drop and a new technique for stress magnitude measurement, J. Geophys. Res., 99, 9373-9390, 1994.

Bauer, S. J., and B. Johnson, Effects of slow uniform heating on the physical properties of the Westerly and Charcoal granites, Proc. U.S. Rock Mech. Symp., 20th, 7-14, 1979.

Brantley, S. L, B. Evans, S. H. Hickman, and D. A. Crerar, Healing of microcracks in quartz: Implications for fluid flow, Geology, 18, 140-144, 1990.

Christensen, N., Compressional wave velocities in metamorphic rocks at pressures to 10 kilobars, J. Geophys. Res., 70, 6147-6164, 1965.

Fredrich, J. T., and T.-F. Wong, Micromechanics of thermally induced cracking in three crustal rocks, J. Geophys. Res., 91, 12,743-12,764, 1986.

Gorbatsevich, F. F., Y. P. Smirnov, N.E. Galdin, and N.V. Sharov, Rock elastic properties, in Archean Complex in the Section of the Kola Super-deep Well (SD-3), pp. 39 43, Kola Science Centre of the USSR Academy of Sciences, Apatity, Russia, 1991.

Hill, R., The elastic behavior of crystalline aggregate, Proc. Phys. Soc., A65, 349-354, 1952.

Hudson, J. A., Wave speeds and attenuation of elastic waves in material containing cracks, Geophys. J. R. Astron. Soc., 64, 133-150, 1981.

Karus, E. W., O. L. Kuznetsov, Y. I. Kuznetsov, G. E. Rudenko, M. D. Lizinsky, I. V. Litvinenko, and L. L. Kudzinsky, Seismic investigations in the borehole, in The Superdeep Well of the Kola Peninsula, edited by Y. A. Kozlovsky, pp. 351-361, Springer-Verlag, New York, 1987.

Kazansky, V. I. Deep structure of the continental crust and oreforming processes, in Proceedings of the 7th Quadrenial IAGOD Symposium, pp. 69-80, Schweizerbart, Stuttgart, Germany, 1988.

Kern, H., R. Schmidt, and T. Popp, The velocity and density structure of the $4000 \mathrm{~m}$ crustal segment at the KTB drilling site and their relationship to lithological and microstructural characteristics of the rock: An experimental approach, Sci. Drill., 2, 130-145, 1991.

Kowallis, B.J., and H.F. Wang, Microcrack study of granitic cores from Illinois deep borehole UPH $3, J$. Geophys. Res., 88, 7373-7380, 1983.

Kozlovsky, Y. A., The Superdeep Well of the Kola Peninsula, Springer-Verlag, New York, 1987.

Kremenetsky, A. A., The geological nature of seismic boundaries in the continental crust, in Super-Deep Drilling and Deep Geophysical Sounding, edited by K. Fuchs, Y. A. Kozlovsky, A. I. Kriftsov, and M. D. Zoback, pp. 393-407, Springer-Verlag, New York, 1990.

Kremenetsky, A. A., and A. I. Krivtsov (Compiler and Ed., respectively), Models and Cross Sections of the Earth's Crust Based on Super-deep Drilling Data of the USSR, 154 pp., Institute of Mineralogy, Geochemistry and Crystal Chemistry of Rare Elements, Moscow, 1991.

Lebedev, T. S., Investigations of some physical properties of mineral matter under thermodynamic conditions of the Earth's interior, Z. Geol. Wiss., 3, 717-739, 1975. 
Litvinenko, I.V., The seismic boundaries of the Earth's crust within the Baltic shield, in Vostochnaya Chast Baltiyskogo Shchita, Geolgiya i Glubinnoye Stroyeniye (The Eastern Part of the Baltic Shield, Its Geology and Structure at Depth), pp. 151-155, Nauka, Leningrad, 1975.

Lockner, D. A., S. Hickman, J. D. Byerlee, V. Kuksenko, A. Ponomarev, A. Sidorin, and B. Khakaev, Laboratorydetermined permeability of cores from the Kola superdeep well, USSR, Geophys. Res. Lett., 18, 881-884, 1991.

Maury, V., F. J. Santarelli, and J. P. Henry, Core discing: A review, in Proceedings of Symposium on Rock Mechanics in Africa, pp. 221-231, National Group on Rock Mechanics of ISRM, Swaziland, S. Afr., 1988.

Mints, M. V., N. I. Kolpakov, V. S. Lanev, and M. S. Rusanov, The character of the subhorizontal seismic boundaries within the upper part of the Earth's crust (according to the data from the Kola ultradeep well), Geotectonics, Engl. Transl., 21, 444-451, 1987.

Morrow, C., D. A. Lockner, S. Hickman, M. Rusanov, and T. Röckel, Effects of lithology and depth on the permeability of core samples from the Kola and KTB drill holes, $J$. Geophys. Res., 99, 7263-7274, 1994.

Nur, A., and G. Simmons, The origin of small cracks in igneous rocks, Int. J. Rock Mech. Min. Sci., 7, 307-314, 1970.

Obert, L., and D. E. Stephanson, Stress conditions under which core disking occurs, Soc. Min. Trans., 232, 227234, 1965.

Pavlenkova, N.I., The Kola well and its implications for the deep seismic soundings (in Russian), Sov. Geol., 6, 16-23, 1989.

Smith, D. L., and B. Evans, Diffusional crack healing in quartz, J. Geophys. Res., 89, 4125-4135, 1984.

Stephanson, O., T. Savilahti, and B. Bjarnason, Rock mechanics of the deep borehole at Gravberg, Sweden, in Rock at Great Depth, Proceedings of Conference, Pau, France, vol. 2, edited by V. Maury and D. Formaintraux, pp. 863870, A.A. Balkema, Rotterdam, Netherlands, 1989.

Vernik, L., and A. Nur, Petrophysical analysis of the Cajon Pass scientific well: Implications for fluid flow and seismic studies in the continental crust, J. Geophys. Res., 97, 5121-5134, 1992.

Vernik, L., and M. D. Zoback, Effects of rock elastic and strength properties in estimation of the state of stress at depth, in Rock at Great Depth, Proceedings of Conference, Pau, France, vol. 2, edited by V. Maury and D. Formaintraux, pp. 1033-1044, A.A. Balkema, Rotterdam, Netherlands, 1989.

Vernik, L. I., Y. I. Kuznetsov, R. V. Medvedev, and I. A. Turchaninov, Physico-mechanical properties, in The Superdeep Well of the Kola Peninsula, edited by Y. A. Kozlovsky, pp. 394-405, Springer-Verlag, New York, 1987.

Wang, H.F., and G. Simmons, Microcracks in crystalline rock from $5.3-\mathrm{km}$ depth in the Michigan basin, J. Geophys. Res., 83, 5849-5856, 1978.

White, J. E., Seismic Waves: Radiation, Transmission, and Attenuation, McGraw-Hill, New York, 1965.

Zang, A., and H. Berckhemer, Classification of crystalline drill cores from the KTB deep well based on strain, velocity and fracture measurements, Int. J. Rock Mech. Min. Sci. Geomech. Abstr., 30, 331-342, 1993.

S. Hickman and D. Lockner, U.S. Geological Survey, MS 977, 345 Middlefield Road, Menlo Park, CA 94025. (e-mail: hickman@thepub.wr.usgs.gov)

M. Rusanov, Nedra Enterprise, 184415 Zapolyarny, Murmansk Region, Russia.

L. Vernik, Department of Geophysics, Stanford University, Stanford, CA 94305.

(Received November 9, 1993; revised April 8, 1994; accepted May 10, 1994.) 